\title{
ESTÁGIOS IMATUROS DE OEBALUS POECILUS (HETEROPTERA, PENTATOMIDAE) ${ }^{1}$
}

\author{
Caroline Greve ${ }^{2}$ \\ Nora D. F. Fortes ${ }^{3}$ \\ Jocélia Grazia ${ }^{2}$
}

\begin{abstract}
IMMATURES STAGES OF OEBALUS POECILUS (HETEROPTERA, PENTATOMIDAE). The immature stages of the rice bug Oebalus poecilus (Dallas, 1851) are described. The egg and the external morphological characters of the five nymphal stages were described and illustrated. The nymphs were exposed to two different photoperiods to induce seasonal forms to detect morphological differences.
\end{abstract}

KEYWORDS. Oebalus, morphology, nymphs, rice, Pentatomini.

\section{INTRODUÇÃO}

O estudo dos estágios imaturos de insetos tem importância taxonômica, ecológica e econômica. O conhecimento das formas jovens permite o diagnóstico precoce e correto de infestações por pragas e proporciona uma maior eficiência das medidas de controle, já que as formas jovens são mais suscetíveis a produtos químicos, a predadores e parasitos (BRAILOVsKy et al., 1992).

Oebalus poecilus (Dallas, 1851) é uma das principais pragas de arroz do Brasil (Squire, 1934; Amaral, 1949). Segundo Albuquerque (1993), seu ciclo de vida é sincrônico com o das suas plantas hospedeiras: durante o inverno, quando o recurso não está disponível, o inseto entra em estado de dormência, voltando ao estado ativo quando as condições tornam-se favoráveis. Seu sucesso como praga de arroz irrigado está intimamente ligado a este processo, já que o cultivo ocorre justamente durante a fase ativa de $O$. poecilus. VeCCHio et al. (1994) citaram O. poecilus entre as quatro espécies de Pentatomidae que possuem dimorfismo sazonal determinado pelo fotoperíodo, ao descreverem a mesma característica para O. ypsilongriseus (De Geer, 1773). Segundo Albuquerque (1993), em O. poecilus, o estágio fotossensível é o de ninfa, mais precisamente os três primeiros ínstares, ou seja, ninfas expostas a fotoperíodos longos

1. Contribuição n ${ }^{\circ} 397$ do Departamento de Zoologia, Universidade Federal do Rio Grande do Sul (UFRGS).

2. Departamento de Zoologia, Instituto de Biociências, UFRGS, Av. Bento Gonçalves, 9500, Bloco IV, Prédio 43435, 91501-970, Porto Alegre, RS, Brasil. (Bolsista CNPq)

3. Universidade Luterana do Brasil, Faculdade de Biologia, Rua Miguel Tostes 101, 92420-280, Canoas, RS, Brasil. 
(dias de verão) dão origem à forma sexualmente ativa, denominada forma não-hibernante, enquanto que ninfas expostas a fotoperíodos curtos (dias de inverno) dão origem à forma sexualmente inativa e que permanecerá em diapausa durante o inverno, denominada forma hibernante. As formas jovens de O. poecilus foram descritas por SQuire (1934), Amaral (1949) e HALTEREN (1972), que não levaram em consideração a existência de dimorfismo sazonal. SQUIRE (1934) apresentou ilustrações pouco detalhadas da morfologia externa de ninfas e ovo.

Os objetivos foram descrever detalhadamente a morfologia externa dos estágios imaturos de $O$. poecilus e detectar possíveis diferenças entre ninfas das formas hibernante e não-hibernante. Dados sobre a duração dos ínstares, obtidos durante a criação, são incluídos.

\section{MATERIAL E MÉTODOS}

Foram coletados 20 machos e 25 fêmeas da forma hibernante de O. poecilus, em 28.XI.2000, em uma taquareira no município de Eldorado do Sul, Rio Grande do Sul. No laboratório, foram colocados

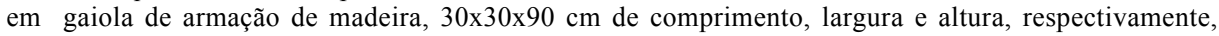
com as faces cobertas por tela de náilon de malha fina. Como alimento, foi oferecido Echinochloa sp. (Poales, Poaceae) (observada em campo como planta hospedeira da espécie), coletada no Instituto Rio Grandense do Arroz (IRGA), Cachoeirinha, RS. O alimento era trocado semanalmente. A gaiola e os ramos das plantas oferecidas como alimento eram vistoriados diariamente. As posturas encontradas foram recolhidas e acondicionadas em potes plásticos, com $9 \mathrm{~cm}$ de diâmetro (na abertura) e tampa vazada coberta por filó de malha fina. O fundo de cada pote foi revestido de papel filtro; continha uma pequena tampa plástica com algodão umedecido em água. Os potes contendo as posturas foram divididos em dois grupos e colocados em duas estufas com fotoperíodos diferentes: um de $12 \mathrm{~h}$, para originar indivíduos não-hibernantes e outro de $10 \mathrm{~h}$, para originar indivíduos hibernantes. O número de posturas destinado a cada tratamento era definido mantendo sempre, em cada um deles, um mínimo de indivíduos para a realização das descrições. As posturas foram observadas diariamente, registrando-se eclosões, mudas e mortes em uma ficha de acompanhamento, exclusiva para cada postura.

Dez ovos e dez ninfas de cada instar, de cada tratamento, foram fixados em álcool $70 \%$ e depositados na coleção do Departamento de Zoologia (UFRGS). Foram obtidos 11 parâmetros morfométricos para cada um dos tratamentos, expressos em milímetros: comprimento total, comprimento e largura da cabeça, comprimento e maior largura do tórax, distância interocular, largura abdominal e comprimento dos artículos antenais (tabs. I, II).

Tabela I. Média e desvio padrão, em mm, dos parâmetros morfométricos tomados dos cinco ínstares ninfais de Oebalus poecilus do tratamento de 10 horas de luz (AI-IV, antenômeros I-IV; CA, comprimento da cabeça; CP, comprimento do pronoto; CT , comprimento total; DI, distância interocular; LA, maior largura abdominal; LC, largura da cabeça na altura dos olhos; LP, largura do pronoto).

\begin{tabular}{lccccc}
\hline & $1^{\circ}$ instar & $2^{\circ}$ instar & $3^{\circ}$ instar & $4^{\circ}$ instar & $5^{\circ}$ instar \\
\hline C T & $1,10 \pm 0,04$ & $1,50 \pm 0,08$ & $2,40 \pm 0,19$ & $3,80 \pm 0,56$ & $5,10 \pm 0,38$ \\
CA & $0,31 \pm 0,05$ & $0,49 \pm 0,04$ & $0,77 \pm 0,10$ & $0,96 \pm 0,10$ & $1,05 \pm 0,18$ \\
CP & $0,25 \pm 0,01$ & $0,39 \pm 0,02$ & $0,66 \pm 0,04$ & $1,20 \pm 0,11$ & $2,15 \pm 0,12$ \\
LA & $0,62 \pm 0,02$ & $0,78 \pm 0,06$ & $1,26 \pm 0,21$ & $2,08 \pm 0,38$ & $3,05 \pm 0,25$ \\
LP & $0,63 \pm 0,02$ & $0,80 \pm 0,04$ & $1,12 \pm 0,08$ & $1,86 \pm 0,10$ & $2,94 \pm 0,16$ \\
LC & $0,49 \pm 0,01$ & $0,61 \pm 0,02$ & $0,82 \pm 0,03$ & $1,17 \pm 0,05$ & $1,53 \pm 0,05$ \\
D I & $0,40 \pm 0,01$ & $0,46 \pm 0,01$ & $0,58 \pm 0,02$ & $0,79 \pm 0,03$ & $0,94 \pm 0,04$ \\
A I & $0,07 \pm 0,01$ & $0,11 \pm 0,01$ & $0,16 \pm 0,01$ & $0,22 \pm 0,02$ & $0,30 \pm 0,02$ \\
A II & $0,11 \pm 0,01$ & $0,21 \pm 0,01$ & $0,32 \pm 0,02$ & $0,53 \pm 0,04$ & $0,89 \pm 0,03$ \\
A III & $0,13 \pm 0,01$ & $0,22 \pm 0,01$ & $0,33 \pm 0,01$ & $0,50 \pm 0,03$ & $0,75 \pm 0,03$ \\
A IV & $0,25 \pm 0,03$ & $0,37 \pm 0,02$ & $0,48 \pm 0,03$ & $0,63 \pm 0,06$ & $0,85 \pm 0,07$ \\
\hline
\end{tabular}

Iheringia, Sér. Zool., Porto Alegre, 93(1):89-96, 30 de março de 2003 
Tabela II. Média e desvio padrão, em mm, dos cinco ínstares ninfais de Oebalus poecilus do tratamento de 12 horas de luz (AI-IV, antenômeros I-IV; CA, comprimento da cabeça; CP, comprimento do pronoto; CT , comprimento total; DI, distância interocular; LA, maior largura abdominal; LC, largura da cabeça na altura dos olhos; LP, largura do pronoto).

\begin{tabular}{lcccccc}
\hline & $1^{\circ}$ instar & $2^{\circ}$ instar & $3^{\circ}$ instar & $4^{\circ}$ instar & $5^{\circ}$ instar \\
\hline C T & $1,10 \pm 0,04$ & $1,60 \pm 0,20$ & $2,40 \pm 0,27$ & $3,50 \pm 0,38$ & 4,99 & $\pm 0,30$ \\
CA & $0,28 \pm 0,05$ & $0,48 \pm 0,04$ & $0,68 \pm 0,09$ & $0,93 \pm 0,14$ & 1,07 & $\pm 0,14$ \\
CP & $0,24 \pm 0,02$ & $0,74 \pm 1,08$ & $0,66 \pm 0,05$ & $1,16 \pm 0,08$ & 2,12 & $\pm 0,14$ \\
LA & $0,68 \pm 0,03$ & $0,87 \pm 0,15$ & $1,40 \pm 0,17$ & $2,00 \pm 0,29$ & 3,13 & $\pm 0,17$ \\
L P & $0,64 \pm 0,02$ & $0,79 \pm 0,02$ & $1,17 \pm 0,06$ & $1,84 \pm 0,13$ & 2,88 & $\pm 0,16$ \\
LC & $0,50 \pm 0,02$ & $0,62 \pm 0,01$ & $0,84 \pm 0,04$ & $1,16 \pm 0,04$ & 1,55 & $\pm 0,06$ \\
D I & $0,39 \pm 0,01$ & $0,46 \pm 0,01$ & $0,59 \pm 0,03$ & $0,78 \pm 0,03$ & 0,97 & $\pm 0,02$ \\
A I & $0,08 \pm 0,01$ & $0,12 \pm 0,01$ & $0,14 \pm 0,01$ & $0,21 \pm 0,01$ & 0,30 & $\pm 0,02$ \\
A II & $0,11 \pm 0,01$ & $0,20 \pm 0,01$ & $0,32 \pm 0,02$ & $0,54 \pm 0,03$ & 0,89 & $\pm 0,03$ \\
A III & $0,13 \pm 0,01$ & $0,22 \pm 0,01$ & $0,33 \pm 0,02$ & $0,51 \pm 0,02$ & 0,75 & $\pm 0,03$ \\
A IV & $0,27 \pm 0,02$ & $0,38 \pm 0,02$ & $0,49 \pm 0,03$ & $0,65 \pm 0,04$ & 0,85 & $\pm 0,07$ \\
\hline
\end{tabular}

\section{RESULTADOS E DISCUSSÃO}

Foram obtidas 134 posturas, das quais 70 foram submetidas ao tratamento de 10 horas de luz e 64 ao tratamento de 12 horas de luz. A média de ovos por postura foi de 13,4 . No tratamento com fotoperíodo de 10 horas, foram obtidos 8 adultos da forma hibernante, 4 machos e 4 fêmeas. No tratamento com fotoperíodo de 12 horas, foram obtidos 7 adultos da forma não-hibernante, sendo 4 machos e 3 fêmeas. Não foram observadas diferenças de morfologia externa entre as ninfas dos dois tratamentos.

Ovo (figs. 1, 2). Forma de barril (fig. 1), com valores médios de 72,8 processos micropilares, altura de $0,93 \mathrm{~mm}$ e largura de $0,71 \mathrm{~mm}$. Coloração verde-clara, tornando-se avermelhada pouco antes da emergência da ninfa. Cório translúcido, com superfície granulosa. Processos micropilares clavados no ápice (fig. 2).

$1^{\circ}$ instar (figs. 3, 6). Ovalado, vermelho-claro logo após a eclosão, cabeça e tórax castanho-claros e abdome vermelho-claro (fig. 6). Pêlos nas antenas e pernas. Cabeça oval (fig. 3), fortemente declivente na metade anterior. Mancha clara arredondada na porção mediana da base da cabeça; $1+1$ linhas claras que se estendem da base dos olhos até a base da cabeça. Clípeo mais longo que as jugas e ambos contornados de negro, com ápice arredondado. Olhos vermelho-escuros. Ocelos ausentes. Antenas castanhoclaras, com anéis vermelho-claros no ápice dos artículos I a III e na base dos artículos III e IV. Artículos II e III subiguais em comprimento; artículo IV aproximadamente $1 / 2 \mathrm{vez}$ mais longo que os artículos II e III; artículo I aproximadamente três quartos do comprimento dos artículos II e III. Rostro castanho-claro, alargado em toda sua extensão e atingindo o terceiro par de coxas. Tórax com linha clara, longitudinal, mediana, estendendo-se do ápice do pronoto até a base do mesonoto. Pronoto, mesonoto e metanoto com margens lisas e emarginadas. Abdome com cinco placas medianas dorsais negras; primeira placa subcilíndrica, com extremidades laterais afiladas, ocupa todo o comprimento do $3^{\circ}$ segmento abdominal e uma pequena porção anterior do $4^{\circ}$ segmento; segunda placa subquadrangular, estende-se da região mediana do $4^{\circ}$ segmento até o terço anterior do $5^{\circ}$; terceira placa ovalada, da região mediana do $5^{\circ}$ segmento até os dois terços anteriores 
do $6^{\circ}$; quarta placa semelhante à primeira, porém menor e localizada junto à margem anterior do $7^{\circ}$ segmento, estende-se por um terço do comprimento deste; quinta placa semicircular, localizada na região mediana do $8^{\circ}$ segmento. Um par de aberturas de glândulas odoríferas nas três primeiras placas dorsais. Placas laterais semicirculares, estendem-se ventralmente. Espiráculos negros, presentes do $2^{\circ}$ ao $7^{\circ}$ segmento abdominal e um par de tricobótrios, do $3^{\circ}$ ao $7^{\circ}$ segmento abdominal, mais internos em relação aos espiráculos e junto à margem posterior do segmento. Pernas castanhas, com face dorsal da tíbia aplainada.

$2^{\circ}$ instar (fig. 7). Ovalado, cabeça e tórax castanho-claros, abdome vermelho- escuro. Pêlos nas antenas e pernas. Pontuações negras na cabeça e no tórax. Cabeça declivente na metade anterior. Artículo antenal I aproximadamente a metade do comprimento do II, II e III subiguais e aproximadamente três quartos do IV. Rostro com segundo artículo afilado, atinge o terceiro par de coxas. Segmentos torácicos com linhas negras nas margens anterior e posterior. Bordas do pro- e mesonoto suavemente serrilhadas. Superfície ventral do abdome com dois pares de tricobótrios por segmento, um na linha dos espiráculos e outro mais interno; manchas castanho-alaranjadas na porção mediana do $4^{\circ}$ ao $9^{\circ}$ segmento. Mancha do $4^{\circ}$ segmento arredondada, do $5^{\circ}$ segmento com forma ovalada e do $6^{\circ}$ ao $9^{\circ}$ com forma subquadrangular. Do $3^{\circ}$ ao $5^{\circ}$ segmento, $1+1$ manchas estreitas junto à margem anterior.

$3^{\circ}$ instar (fig. 8). Cabeça e tórax castanho-escuros a negros. Cabeça levemente declivente na metade anterior. Superfície torácica dorsal enrugada, margens fortemente emarginadas e superfície ventral castanho-escura a negra. No $2^{\circ}$ segmento abdominal, 1+1 manchas negras dorsais alongadas; manchas abdominais ventrais castanho-escuras a negras. Segunda e terceira placas dorsais intumescidas na metade anterior; quinta placa dorsal estende-se por todo comprimento do $8^{\circ}$ segmento. Demais características como no instar anterior.

$4^{\circ}$ instar (fig. 9). Cabeça negra, alongada, não declivente. Jugas suavemente defletidas. Linhas que se estendem dos olhos até a base da cabeça delicadas e quase imperceptíveis. Ocelos presentes; coloração avermelhada. Artículos antenais II e III subiguais e aproximadamente meia vez maiores que o I e menores que o IV. Rostro estreito em toda a sua extensão. Margens laterais do pronoto emarginadas e translúcidas. Margens posteriores do meso- e metanoto marcadamente arredondadas. Início do desenvolvimento das pterotecas. Demais características como no instar anterior.

$5^{\circ}$ instar (figs. $4,5,10$ ). Coloração da cabeça variando de caramelo-clara a negra, com pontuações negras concentradas na base e nas jugas; nas ninfas com cabeça carameloclara, manchas negras arredondadas entre os olhos estão presentes. Artículos antenais II a IV subiguais. Superfície dorsal do tórax com pontuações negras. Margens do pronoto visivelmente translúcidas. Pterotecas não atingem a margem posterior do $5^{\circ}$ segmento abdominal. Início da diferenciação de genitália externa, podendo-se observar, nas fêmeas, o $8^{\circ}$ segmento fendido longitudinalmente na porção mediana. No macho, este segmento apresenta-se íntegro.

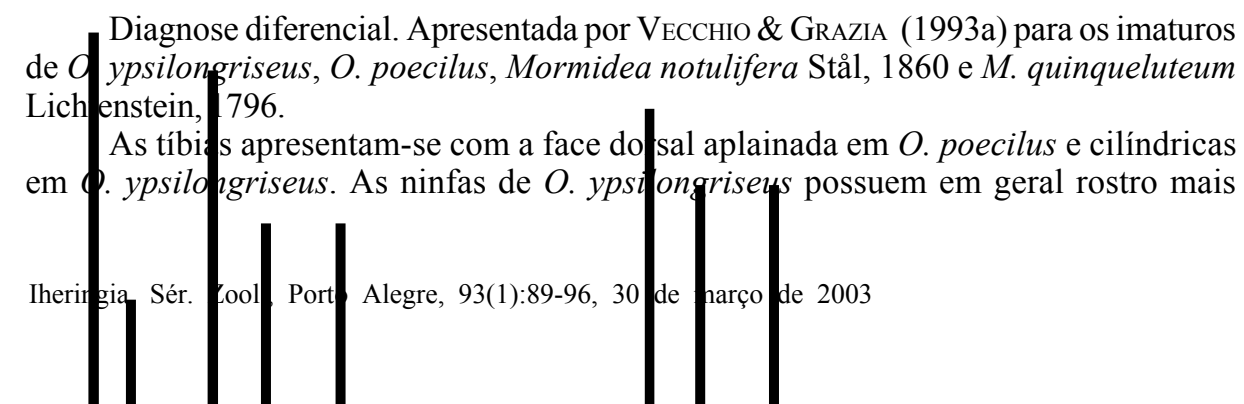



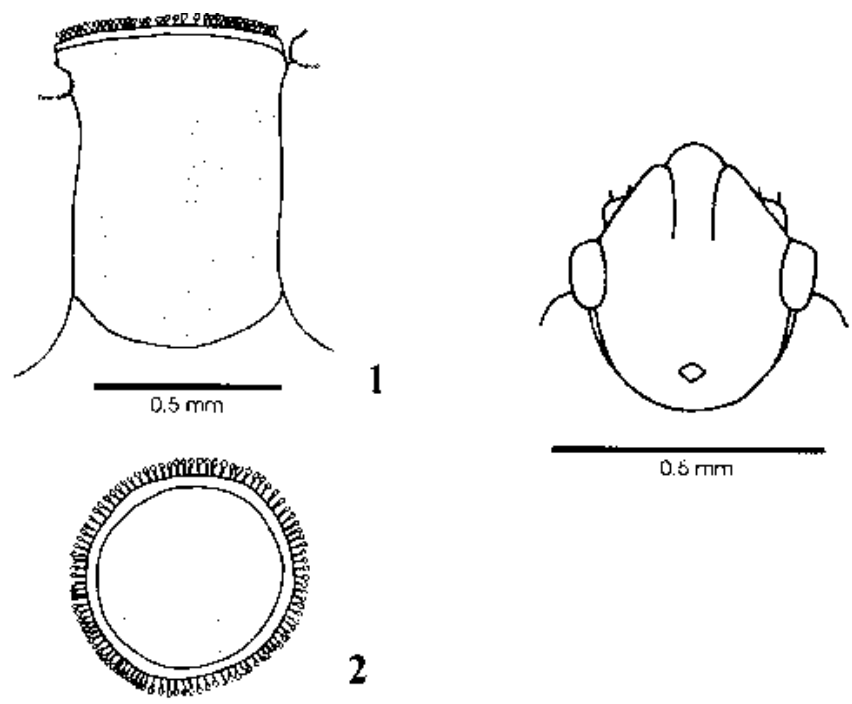

3
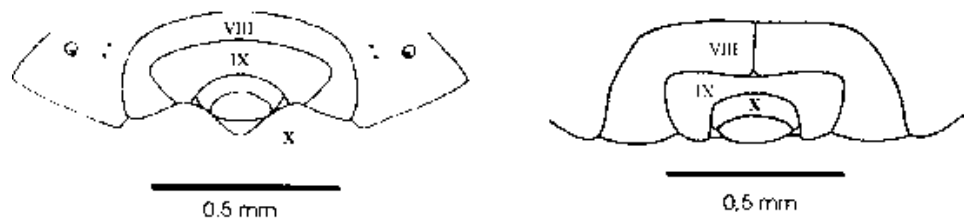

4

5

Figs. 1-5. Oebalus poecilus: 1, 2, ovo, lateral e superior respectivamente; 3, cabeça de ninfa, dorsal; 4, 5 , genitália externa de ninfa de $5^{\circ}$ instar, ventral, macho e fêmea respectivamente (VIII, oitavo segmento abdominal; IX, nono segmento abdominal; X, décimo segmento abdominal).

curto que $O$. poecilus, atingindo o $2^{\circ}$ par de coxas ou a margem posterior do $2^{\circ}$ urosternito; no $3^{\circ}$ instar, o rostro atinge o $3^{\circ}$ par de coxas, o que é característica constante nos cinco ínstares de $O$. poecilus.

Em relação ao padrão de coloração, imaturos de $O$. poecilus apresentam durante todo o desenvolvimento um padrão de distribuição de anéis claros junto às articulações dos segmentos antenais: no ápice dos segmentos I a III, na base dos segmentos III e IV. Os imaturos de O. ypsilongriseus apresentam anéis claros junto às articulações dos três primeiros segmentos antenais no primeiro instar e junto às articulações de todos os segmentos a partir do $2^{\circ}$ instar. As ninfas dos dois primeiros ínstares de $O$. poecilus e $O$. ypsilongriseus podem ser diferenciadas pela coloração da cabeça e do tórax, que na primeira espécie apresenta-se castanho-clara e, na segunda, negra. 
Ninfas de $2^{\circ}$ instar podem ser diferenciadas pelas pontuações negras na cabeça e no tórax de $O$. poecilus e de estrias finas na cabeça e no tórax de $O$. ypsilongriseus, placas laterais de O. ypsilongriseus possuem o centro descolorido, o que não acontece em $O$. poecilus. A diferença mais marcante entre as ninfas de $3^{\circ}$ instar das duas espécies é a presença de placas laterais: em $O$. ypsilongriseus são translúcidas e em $O$. poecilus negras.

Os $3^{\circ}$ e $4^{\circ}$ ínstares das duas espécies apresentam cabeça e tórax negros, exceto nas formas claras de $O$. ypsilongriseus, que têm coloração acinzentada no $3^{\circ}$ instar, e amareloesverdeada no $4^{\circ}$ instar. Tal diferenciação, ao contrário do que é relatado por SQUIRE (1934), Amaral (1949) e Vecchio \& Grazia (1993a), não é observada nas ninfas de $O$. poecilus aqui estudadas. Esta diferença na coloração pode ser atribuída ao efeito de diferentes dietas, conforme SCHWERTNER et al. (2002), que descreveram ninfas de $4^{\circ}$ e $5^{\circ}$ ínstares de Acrosternum ubicum Rolston, 1983 com formas clara e escura, cuja proporção variou de acordo com o tipo de alimento oferecido.

$\mathrm{O} 4^{\circ}$ instar de $O$. ypsilongriseus não apresenta margens laterais translúcidas, ao contrário das ninfas de $O$. poecilus.

Ninfas de $5^{\circ}$ instar de ambas as espécies apresentam variação de cor, no entanto em $O$. poecilus esta variação está restrita à cabeça (negra ou castanho-clara), enquanto em O. ypsilongriseus a variação atinge cabeça e tórax (negros ou amarelo-esverdeados). $\mathrm{O}$ clípeo é mais longo que as jugas no $5^{\circ}$ instar de $O$. poecilus, enquanto que em $O$. ypsilongriseus o clípeo e as jugas são iguais.

Duração dos ínstares. Observando-se a duração média, em dias, de cada instar, obtida para cada tratamento (tab. III), verifica-se que o $1^{\circ}$ instar é o mais curto e o $5^{\circ} \mathrm{o}$ mais longo. Esta é uma característica geral para a família, ocorrendo também em $O$. ypsilongriseus (VECCHIO \& GRAZIA, 1993b). As maiores diferenças na duração dos ínstares de $O$. poecilus e $O$. ypsilongriseus são observadas entre as ninfas de $4^{\circ}$ instar, que nos dois tratamentos de $O$. poecilus apresentaram período mais longo de duração $(5,3 \pm 2,01$ dias hibernantes e 7,3 $\pm 2,8$ dias não-hibernantes) do que as de $O$. ypsilongriseus (4,06 $\pm 0,85$ dias). Fica evidenciada também a diferença na duração do $5^{\circ}$ instar das ninfas do tratamento de maior período de luz (não-hibernantes) de O. poecilus $(11,3 \pm 2,98$ dias) e do $5^{\circ}$ instar de $O$. ypsilongriseus $(6,72 \pm 1,25$ dias), o que não é observado em relação às ninfas do $5^{\circ}$ instar do tratamento de menor período de luz (hibernantes). O tempo médio de $2^{\circ}$ instar (fase em que começa a alimentação) a adulto, para ninfas não-hibernantes, foi de 28,7 \pm 4,31 dias e para ninfas hibernantes, 20,1 $\pm 1,95$ dias. Esta diferença sugere influência de algum fator no desenvolvimento dos imaturos nos diferentes tratamentos.

Tabela III. Duração média, em dias, do estágio de ovo e dos ínstares ninfais de Oebalus poecilus para os tratamentos de fotoperíodo de 10 horas (hibernantes) e de 12 horas (não hibernantes).

\begin{tabular}{ccc}
\hline & Hibernante & Não-hibernante \\
\hline Ovo & $4,6 \pm 0,92$ & $5,6 \pm 1,43$ \\
$1^{\circ}$ & $2,9 \pm 0,33$ & $2,8 \pm 2,19$ \\
$2^{\circ}$ & $4,5 \pm 1,51$ & $4,2 \pm 1,30$ \\
$3^{\circ}$ & $3,9 \pm 1,07$ & $4,5 \pm 1,26$ \\
$4^{\circ}$ & $5,3 \pm 2,01$ & $7,3 \pm 2,80$ \\
$5^{\circ}$ & $6,9 \pm 0,99$ & $11,3 \pm 2,98$ \\
\hline & & \\
Iheringia, St: Z & & \\
\end{tabular}



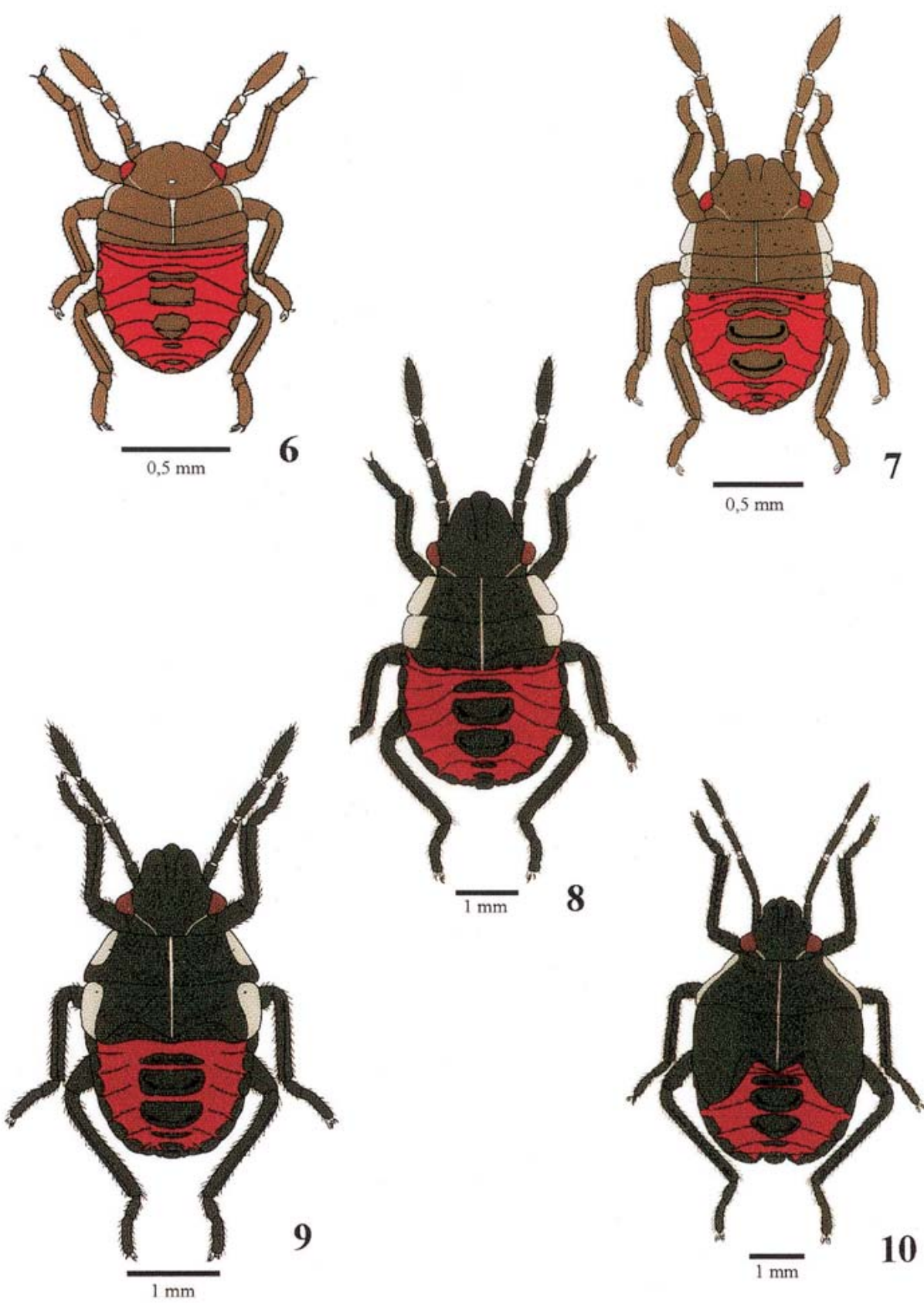

Figs. 6-10. Morfologia externa da ninfas de Oebalus poecilus: 6, $1^{\circ}$ instar; 7, $2^{\circ}$ instar; $8,3^{\circ}$ instar; 9, $4^{\circ}$ instar; $10,5^{\circ}$ instar. 


\section{REFERÊNCIAS BIBLIOGRÁFICAS}

Albuquerque, G. S. 1993. Planting time as a tactic to manage the small rice stink bug, Oebalus poecilus (Hemiptera, Pentatomidae), in Rio Grande do Sul, Brazil. Crop Prot., Oxford, 12(8):627-630.

Amaral, S. F. 1949. Biologia e importância econômica do percevejo do arroz, no Estado de São Paulo. Biológico, São Paulo, 15(3):47-58.

Brailovsky, H.; Cervantes, L. R. \& Mayorga, C. 1992. Hemiptera: Heteroptera de Mexico XLIV. Biologia, estádios ninfales y fenologia de la tribu Pentatomini (Pentatomidae) en la Estación de Biologia Tropical "Los Tuxtlas", Vera Cruz. Mexico, D.F., Universidad Nacional Autonoma de Mexico, Instituto de Biologia. 204p. (Publicaciones Especiales, 8)

Halteren, P. van. 1972. Some aspects of the biology of the paddy bug, Oebalus poecilus (Dall.), in Surinam. Surinaam, Wageningen, 2:23-33.

Schwertner, C. F.; Albuquerque, G. S. \& Grazia, J. 2002. Descrição dos estágios imaturos de Acrosternum (Chinavia) ubicum Rolston, 1983 (Heteroptera: Pentatomidae) e efeito do alimento no tamanho e coloração das ninfas. Neotrop. Ent., Londrina, 31(4):571-579.

Squire, F. A. 1934. A study of Mormidea poecila Dall. Agr. Jour. Brit. Guiana, Georgetown, 5(4):245-252.

Vecchio, M. C. del \& Grazia, J. 1993a. Estudo dos imaturos de Oebalus ypsilongriseus (De Geer, 1773): II. Descrição das ninfas (Heteroptera: Pentatomidae). Anais Soc. ent. Bras., Londrina, 22(1):109-120.

1993b. Estudo dos imaturos de Oebalus ypsilongriseus (De Geer, 1773): III. Duração e mortalidade dos estágios de ovo e ninfa (Heteroptera: Pentatomidae). Anais Soc. ent. Bras., Londrina, 22(1):122-129.

Vecchio, M. C. Del; Grazia, J. \& Albuquerque, G. S. 1994. Dimorfismo sazonal em Oebalus ypsilongriseus (De Geer, 1773) (Hemiptera: Pentatomidae) e uma nova sinonímia. Revta bras. ent., São Paulo, 38(1):101-108.

Recebido em 11.06.2002; aceito em 12.12.2002. 